\title{
Felicidad versus happycracia
}

Happiness, versus happycracia

\section{Dr. Marino Latorre Ariño}

Universidad Marcelino Champagnat

hmarinola@yahoo.es
Recibido el 11/10/2018

Revisión del 14/01 al 30/05/2019

Publicación 26/06/2019

\section{Resumen}

En este artículo se realiza una reflexión sobre el concepto de felicidad a través de la historia y su relación con los tres referentes de la filosofía clásica: la verdad, el bien y la belleza. Se discute sobre si las tecnologías digitales pueden conducirnos o apartarnos de la felicidad. El artículo intenta dar respuestas a preguntas como las siguientes: ¿Se puede educar para desarrollar una biografía feliz? ¿Cuánto influye la educación para lograr la felicidad? ¿El esfuerzo y el trabajo bien hecho pueden ser fuente de felicidad? También se aborda, con sentido crítico, el concepto de happycracia y su significado en relación con la psicología positiva, así como con la ideología y los intereses de todo tipo que subyacen en muchas propuestas actuales para conseguir una vida feliz.

Palabras clave: coaching, felicidad, happycracia, mindfullnness, psicología positiva. 


\begin{abstract}
This article reflects on the concept of happiness throughout history, and its relationship with the three reference points of classical philosophy: the truth, the goodness and the beauty. It discusses whether the digital technologies are leading us to or move us away from happiness. The article tries to give an answer to questions such as, can we educate to develop a happy life? What is the influence of education to reach happiness? Can the effort and the well-done work be a source of happiness? The article deals also, in a critical manner, with the concept of happycracy and its meaning in relation to Positive Psychology, as well as the ideology and the different types of interest that underlie many current proposals to achieve a happy life.
\end{abstract}

Keywords: Coaching, Happiness, Happycracy, Mindfulness, Positive Psychology

\title{
Résumé
}

Cet article est une réflexion sur le concept du bonheur à travers l'histoire, et sa relation avec les trois points de référence de la philosophie classique: la vérité, la bonté et la beauté. Il examine si les technologies digitales nous approchent ou nous éloignent du bonheur. L'article essaie de trouver une réponse à des questions telles que : Pouvons-nous éduquer pour développer une existence heureuse? Quelle est l'influence de l'éducation pour atteindre le bonheur? Est-ce que l'effort et le travail bien accompli peuvent devenir une source de bonheur? D'une manière critique, l'article aborde le concept de happycratie et sa signification en rapport avec la psychologie positive, ainsi qu'avec les idéologies et les différents intérêts qui se cachent sous les propositions actuelles pour atteindre une vie heureuse.

Mots-clé : Coaching, Bonheur, Happycratie, Mindfulness, Psychologie positive 


\section{Introducción}

El hombre, desde que es homo sapiens, ha ido en búsqueda de los tres grandes referentes de la filosofía clásica: la verdad, el bien y la belleza. Sócrates (Collina, 2016, 64 y ss.) concebía la verdad como el resultado de un proceso de búsqueda compartido con otras personas que en cualquier momento podía ser repensada y perfeccionada. Los instrumentos que utilizaba para encontrar la verdad eran la reflexión y el diálogo que constituyen el elemento central del método socrático de búsqueda de la verdad. El diálogo se produce a través de "la dialéctica socrática" que utilizaba preguntas concretas según sugería el propio diálogo. El significado de la palabra diálogo (סıáরoyos) denota el instrumento de intercambio de información en búsqueda de algo.

La pregunta más frecuente de Sócrates era ¿qué es? (Tí $\varepsilon \sigma T I=$ tì ésti = qué es). A través de la ironía (E⿱丷ipoveı = eironéia = disimulo), Sócrates conducía a su interlocutor a situaciones ambiguas o irresolubles para que cayera en la cuenta de que estaba equivocado. La ironía era el momento destructivo del diálogo socrático, pero no surgía para humillar al oponente, sino para que se diera cuenta del error. Pasado este momento venía el momento constructivo; era la mayéutica

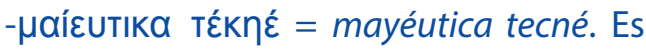
decir, la técnica de dar a luz las ideas que ya se encuentran dentro de la mente de cada uno -el alma-- de la misma forma como las matronas ayudan a nacer a los niños. Sócrates era un "obstetra de las ideas" y utilizaba como herramienta la mayéutica. Lo narra platón en Teeteto $(1946,15,1 b)$ y en Menon (1946, 82, b-e).

La reflexión moral de Sócrates gira entorno a la noción del bien y la virtud (apetć = areté). La virtud, para el filósofo, es cosa de humanos que, entre los griegos de su tiempo, se identificaba con la valentía, la entereza, el honor, el vigor físico, etc., y eran dones recibidos de la naturaleza o de la voluntad de los dioses. Sócrates se preguntó ¿qué significa cultivar la virtud?, ¿cuáles son los comportamientos humanos que los vuelven virtuosos? Sócrates va más allá de la concepción de sus conciudadanos y afirma que la virtud es "una cualidad interior del ser humano" que puede 
enseñarse mediante la paideia (таıбहía, "educación" o "formación"). La virtud no tiene nada que ver con el exterior del ser humano ni con el reconocimiento público por los conciudadanos. Hay que ser virtuoso para estar de acuerdo con la propia conciencia, dice Sócrates a través de Platón (Banquete, 1946, 21 6d).

En consecuencia, para Sócrates "el arte del buen vivir" es el de "comportarse bien" desde el punto de vista ético. Quiere decir que lo esencial del ser humano es pensar, reflexionar, y en consecuencia vivir de manera virtuosa, $y$, de esa forma, desplegar al máximo estas características. Razón y virtud están unidas indisolublemente. La virtud se convierte en conocimiento y este en sabiduría, pues el ser humano solo puede distinguir lo que es bueno o malo a través de la razón y el conocimiento.

Sócrates se pregunta en el final de Protágoras (1946) ¿cómo debemos valorar a quienes conociendo el bien deciden hacer el mal? Sócrates dice que este es "el mayor ejemplo de ignorancia". El bueno de Sócrates daba por supuesto que "el que conoce el bien lo practica". Es el inicio del racionalismo moral que tanta influencia tuvo en la llustración del siglo XVIII, y que lleva a las siguientes conclusiones: 
Platón introduce el mundo de las ideas y de las formas. La idea o forma con estatus privilegiado, es la idea del bien o de la belleza, que unifican todos los demás conceptos y son la causa de ellos. La forma resplandeciente del bien ilumina todas las demás formas. Para Platón el bien y la belleza son la misma cosa: "Lo que da al alma la facultad de conocer la idea del bien, es el principio de la verdad" (República, 1946, 508e y 509b). Por otra parte, Aristóteles afirmaba que "la virtud es el hábito de obrar el bien" (Ética a Nicómaco, 1947, Libro II, capítulo 5).

Hasta aquí hemos presentado la relación entre los tres elementos clásicos de la filosofía: el bien, la verdad, y la belleza. Pero, ¿cómo se relaciona lo anterior con la felicidad? Sócrates considera que el fin que persigue todo ser humano es conseguir la felicidad y se pregunta: ¿qué es la felicidad? Él mismo responde e identifica la felicidad con el perfeccionamiento moral de la persona. En consecuencia, la felicidad no está en las riquezas, en los bienes materiales, en los placeres, etc., está en la perfección y en el recto actuar de la persona.

Para Sócrates ética y felicidad se identifican; solo el hombre virtuoso (sabio y justo) puede ser realmente feliz. El malvado e injusto es un ignorante y no puede ser feliz. En Gorgias (1946) Platón pone en labios de Sócrates las siguientes palabras: "Sostengo que el que es bueno y honrado, sea hombre o mujer, es feliz y que el malvado e injusto es desgraciado" (470e).

Resumiendo, podemos decir que Sócrates identificaba el conocimiento con la virtud y ahora vemos que identifica la virtud con la felicidad. El conocimiento (la sabiduría) conduce a la virtud y la virtud lleva a la felicidad. De esta manera, para Sócrates la felicidad procede no de los bienes y placeres materiales, sino de estos tres elementos: - El dominio de sí (control de las pulsiones del cuerpo, control del placer físico inmediato; sin el dominio de sí el hombre se convierte en un animal salvaje).

- La libertad interior. Platón no habla de las libertades y derechos políticos de los ciudadanos, sino de los individuos; ya no es la libertad exterior, sino la libertad interior y personal; poner en práctica el autodominio es llegar a ser libre interiormente $\mathrm{y}$ romper cualquier esclavitud. 
- La autosuficiencia (autarquía) o sabiduría del hombre virtuoso. El hombre sabio y virtuoso no necesita de las cosas para ser feliz, pues encuentra en su interior las razones para serlo.

Platón narra "el mito del carro alado" (Fedro, 1946, 249c), acerca del alma y de la dificultad de alcanzar la virtud y la felicidad. El ser humano se asemeja a un carruaje conducido por un auriga (el alma racional) que guía dos briosos caballos. Uno de los caballos es blanco, bueno y hermoso el cual representa la parte noble y racional del alma; el otro caballo es oscuro y feo, y representa las pasiones a las que está sometida el alma.

El trabajo del auriga es dirigir el carro, pero este es un trabajo difícil. La fuerza del caballo blanco (el bien) consiste en llevar hacia arriba lo pesado, elevándose hacia el lugar en donde habitan los dioses (mundo de las ideas, mundo inteligible que no es posible apreciar con los sentidos), pues el mundo donde viven los dioses es hermoso, sabio y bueno y hace crecer las alas del carro.

En cambio, la fuerza del caballo oscuro, conduce a todo lo contrario, es decir, arrastra al mundo de las cosas materiales, el mundo sensible, al mundo perceptible a través de los sentidos y de las pasiones.

Este mito resume perfectamente la propuesta que recorre la totalidad de la filosofía platónica: realizar en esta vida y de forma radical la verdad, el bien y la belleza, ya que "lo divino es hermoso, sabio y bueno y esto es lo que más alimenta y hace crecer las alas" (Fedro, 1946, 246, d3-248d). El concepto "alma" en Platón es el ánima, aquello que nos "anima" y da vida, igual que al resto de "animales". Prescindiendo de concepciones trascendentes podemos decir que el alma es como el ADN que tiene la información básica de cada ser humano y que se despliega en una personalidad concreta y diferente, de la cual surgen todas nuestras tendencias, nuestros pensamientos y nuestras acciones.

¿Qué sucede cuando el auriga no es capaz de controlar los dos briosos caballos del carro alado y se deja llevar por las pasiones impulsadas por las ideologías de la sociedad? Eso ya ha sido experimentado a través de la Historia en regímenes totalitarios con consecuencias desastrosas para 
la humanidad (comunismo, nacionalsocialismo, etc.). ¿Por qué ocurre esto? Porque, como decía Chesterton, "el problema de no creer en Dios no es que uno no crea en nada, es que se cree cualquier cosa". Y yo añadiría que cuando uno se convierte en dios y puede fijar los principios rectores de la vida, las normas, las leyes, la moral, etc. a su antojo, la catástrofe está garantizada. De ahí que hayan sido, y sean los peores regímenes que ha sufrido la sociedad, los más destructivos, los más asesinos, los que convierten al ser humano en un esclavo, un animal irracional, no en persona humana, sino persona animal no controlada por el auriga de la moral civilizada, sino por el capricho de quien tiene el poder y pone nombre a las cosas, -ejemplo paradigmático los regímenes antes citados-, porque quien tiene el poder de nombrar las cosas es el que tiene realmente el poder. Los clásicos dirían simplemente: Quia nominor leo (porque me llamo león).

Por otro lado, pero continuando con la idea de la felicidad, Aristóteles, discípulo de Platón, partía de dos premisas o hipótesis:

- El hombre cuando actúa busca un fin.
- $\quad$ El fin que busca el hombre cuando actúa es la felicidad.

Para Aristóteles conseguir la felicidad es el fin supremo de todo hombre. Identifica la felicidad con la eudaimonía

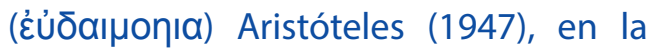
misma línea de sus maestros, afirma: "Tanto la gente del pueblo como los hombres cultos piensan que vivir bien y obrar rectamente es lo mismo que ser feliz". Ante la pregunta de qué es el bien para el hombre, Aristóteles contesta que para saberlo hay que preguntarse cuál es el fin de la vida del hombre. Conociendo eso sabremos qué tiene que hacer el hombre para alcanzar el bien y llegar a ser feliz. La eudaimonía es la felicidad que proporciona el desarrollo integral de la persona; es encontrarse bien consigo mismo al sentirse interiormente con una vida plena y desarrollada. En consecuencia, la felicidad y la vida plena dependen de cada uno, de la manera de actuar en cada situación y no de agentes externos.

La virtud en griego se expresa por la palabra areté (ápeté). Areté es la realización perfecta y excelente de algo; si se trata de una persona, involucra el desarrollo tanto de las virtudes morales 
como de las capacidades intelectuales. Para Aristóteles "la virtud es el hábito de obrar bien"; es comportarse virtuosamente de forma habitual, pues el hábito y la práctica constante es lo que determina la virtud. En su Ética a Nicómaco (1947), Aristóteles afirma:

Sócrates creía que el fin de la vida era conocer la virtud y para ello preguntaba, ¿cuál es la esencia de la justicia, de la valentía, etc.? [...] Pero lo importante no es saber lo que es la virtud, sino cómo surgen las virtudes. La virtud y el vicio están asociados a acciones concretas.

En consecuencia, para ser virtuoso no basta con conocer lo que es bueno o malo -como decían Sócrates y Platón- sino que hay que practicar el bien. Un buen acto es mejor que una buena intención. No somos virtuosos por naturaleza, sino que alcanzamos la virtud cuando nos comportamos éticamente en la vida de forma habitual.

Zenón de Citio (334 a.C.-260 a.C.) filósofo representante del estoicismo, sostenía que la sabiduría, el bien y la felicidad dependen de la comprensión integral de la naturaleza y del universo. Esta comprensión se produce a través del conocimiento de la física y de las ciencias de la naturaleza, de la epistemología (teoría del conocimiento) y de la ética. Entre los estoicos de Roma destacaban Séneca (4 a.C.-65 d.C.) y Epicteto (50-120 d.C.). Es este último quien estudió la autonomía personal y la libertad como fuentes de la moralidad. Epicteto distingue entre lo que está en nuestro poder (nuestra actitud frente a la vida) y lo que no depende de nosotros (el éxito en la vida) y así diferencia libertad y determinismo.

La pregunta de los estoicos era la siguiente: ¿qué debo hacer para ser feliz? La respuesta consiste en que la felicidad personal se alcanza practicando la virtud, lo cual implica ayudar y respetar a los demás. Para los estoicos, la felicidad consiste en poseer la sabiduría y la virtud (el que es sabio práctica la virtud). El enfoque es intelectualista y racionalista y está en la línea socrática. Por eso, la salud y los bienes materiales pueden ser buenos en la medida en que ayuden a practicar la virtud.

El estado emocional que permite llegar a la felicidad viene definido en la filosofía helenística por la palabra ataraxia 


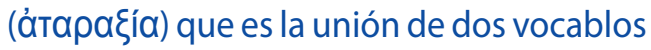
y que significa ausencia de perturbación. Es un estado emocional caracterizado por la imperturbabilidad y la calma de las emociones gracias a la paz interior y a la disminución de los deseos y las pasiones que perturban nuestro ánimo. "No se trata de tener mucho, sino de desear poco" dicen los estoicos. Según este planteamiento, la ataraxia sería la manera de conseguir una felicidad plena sin perturbaciones exteriores.

Platón en La República (1946) y Las leyes (1946) dice que la práctica de "las leyes harían a una ciudad feliz" y, por eso, Aristóteles consideraba que la política era la ocupación más noble porque se ocupaba de la felicidad común. Esa fue también la idea de las revoluciones ilustradas europeas del siglo XVIII. La declaración de Independencia de Estados Unidos (1776) proclama que el fin del gobierno es "alcanzar la seguridad y la felicidad" de los ciudadanos. La filosofía estoica y religiosa la nombran como llegar al estado del nirvana, la ataraxia, la gloria del cielo, etc. 


\section{Las tecnologías, la verdad y la felicidad}

Con la aparición de las tecnologías digitales surge la realidad virtual, (la vida no real). Es la realidad aumentada que no es solo la realidad virtual, pues la tecnología digital permite una mezcla de las dos realidades: la real y la virtual. Con la ayuda de la tecnología, la información sobre el mundo real se convierte en virtual. Esta información artificial puede ser almacenada y recuperada; es como una capa de información en la parte superior de la visión del mundo real. Podemos decir que las tecnologías han posibilitado la "sociedad aumentada" (SA), la "sociedad en red".

La sociedad aumentada ha producido una revolución social, cultural, creativa y con ello una verdadera revolución antropológica y social; han aparecido, de forma progresiva, las TIC (tecnologías de la información y la comunicación), las TAC (tecnologías del aprendizaje y el conocimiento), las TEP (tecnologías del empodera-miento y la participación), las TIP (Tecnologías de la Investigación y Publicación) que permiten la creación y compartición de información y conocimiento y las TES (Tecnología,
Entendimiento y Sabiduría); esta última es la tecnología pensada como sophia

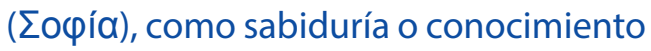
supremo. Esa es la misión de la educación superior. "La escuela es conocimiento; en la universidad se aprende sabiduría" (Inscripción en la Assumption University de Bangkok, Tailandia).

Cuán lejos está la última concepción sobre la tecnología (TES), cuando se utiliza de forma abusiva para exhibirse de vacaciones en fotografías tomadas en hermosas playas caribeñas, danzando y comiendo-bebiendo, etc., y como expresión de la felicidad que produce la buena vida. Hasta ese punto se han materializado y pragmatizado los bellos conceptos clásicos de felicidad y sabiduría. Si buscan la palabra sophia en Internet aparecerá la descripción de un robot que resuelve los problemas de la casa y hace la vida menos trabajosa.

Cuando se habla de la universidad, se tiene la impresión de que el objetivo últimoeslaadquisición del conocimiento. Este es uno de los objetivos pero no es el único ni el más relevante; existe algo 
más importante que eso; se asiste a la escuela y a la universidad para aprender a vivir mejor y desarrollar una biografía feliz, y ser ciudadanos útiles a la sociedad en la que se vive. Esto se consigue mediante la adquisición de la sabiduría; es más un aprendizaje del estudiante que una lección del profesor y es fruto de la observación de los hechos de la naturaleza, de la sociedad, de la vida misma, de la reflexión, interiorizacióny de las conclusiones personales. La sabiduría no viene de fuera, no es la erudición libresca, sino que brota de dentro. $Y$ podemos observar que la mucha cultura no es equivalente a mucha sabiduría, pues existen analfabetos que poseen mucha sabiduría de vida y hombres cultos que no poseen ninguna.

La vida es un conjunto de opciones personales. La calidad de nuestras opciones es la que define la calidad de nuestra vida. Lo más difícil en la vida es saber qué puentes hay que construir y cuáles hay que destruir, pues en la vida hay decisiones que no son fáciles de tomar ya que la sabiduría tiene pocas certezas y muchas dudas y preguntas. La ignorancia, por el contrario, tiene demasiadas certezas y pocas preguntas.
Wilhelm von Humboldt -fundador de la universidad de Berlín- dijo: "El objetivo de la existencia es la destilación de la mayor cantidad posible de experiencias en la vida, para adquirir la sabiduría". Y Kant (1990): "La sabiduría es más que ciencia; es saber vivir y tener razones para vivir [...] Ciencia es conocimiento organizado, sabiduría es vida organizada y con sentido". No todo conocimiento es sabiduría. La sabiduría está más en el corazón que en la cabeza; la sabiduría es el conocimiento de la verdad del ser y de la vida; la sabiduría gobierna el ser, muestra el valor de las cosas, enseña a comportarse y exige la actuación según la conciencia. En cambio, el conocimiento y la ciencia están en la cabeza pues el conocimiento es la verdad de las cosas; el conocimiento gobierna el saber, dice cómo son y cómo funcionan las cosas, qué puedo hacer con ellas (técnica) etc. y exige siempre el razonamiento y la comprensión.

La utilización sinérgica del conocimientosabiduría es fuente de vida para el que la posee, pues orienta sobre el camino que hay que seguiry da sentido a la existencia. Tarde o temprano todos los humanos, de todos los tiempos y culturas, se preguntan: ¿Qué sentido tiene la vida? La 
respuesta exige meditación y reflexión; requiere sabiduría. "La sabiduría se consigue en la universidad de la vida (...); no es un producto de la escuela, sino el resultado del esfuerzo de toda la vida" (Einstein). Dreze y Debelle como se citó en Kaplun, 1983, p. 39), hablando a profesores universitarios, les decían: "Los hombres son hombres antes de ser abogados, médicos, comerciantes o industriales. Si vosotros, docentes, hacéis de ellos hombres capaces y sensatos, ellos se transformarán, por sí mismos, en abogados, médicos, comerciantes e industriales, capaces y sensatos". De ahí que todo profesor tenga que ser, ante todo, un maestro en humanidad; solo así formará buenas personas. Todo lo demás viene después.

La misión del profesor es provocar en los estudiantes la reflexión, la búsqueda de sentido, pues la sabiduría es, sobre todo, el resultado del crecimiento interior de la persona. El Eclesiastés (3, 30-31) recomienda: "El hombre inteligente reflexiona sobre las palabras de los sabios y con oído atento desea la sabiduría".

El proceso final que resume todo el discurso anterior se pude resumir en esta secuencia: 


\section{La educación y la felicidad}

Como hemos indicado, Sócrates afirma que la virtud es "una cualidad interior del ser humano" que puede enseñarse mediante la paideia (la educación). Hay que ser virtuoso para estar de acuerdo con la propia conciencia (Platón, Banquete (1871, 21 6d). En consecuencia, decía Sócrates, "el arte del buen vivir" es el de "comportarse bien" desde el punto de vista ético. Quiere decir que lo esencial del ser humano es pensar, reflexionar, y en consecuencia, comportarse de manera virtuosa $y$, de esa forma, desplegar al máximo todas las potencialidades del ser humano.

Sin embargo, en el mundo globalizado y posmoderno se promueven formas de existir que buscan "no tocar lo esencial de la vida", sino que se mueven en la superficie de lo vital. Parece como si, en todos los niveles, viviéramos, cada vez más, una vida desprovista de sustancia. Se consume cerveza sin alcohol, carne sin proteínas, café sin cafeína, leche desnatada, y, eventualmente, sexo virtual, sin sexo real...

Zizez (2018) sociólogo, psicoanalista y filósofo esloveno contemporáneo, dice:
Parece como si en todos los niveles viviéramos, cada vez más, una vida desprovista de sustancia. Se consume cerveza, sin alcohol, carne sin proteínas, café sin cafeína, y, eventualmente, sexo virtual... sin sexo... [...] El amor se experimenta como una gran desgracia, un parásito monstruoso, un estado de emergencia permanente que arruina los pequeños placeres... [...] Estamos atrapados en una competición malsana, en una red absurda de comparaciones con los demás. No prestamos suficiente atención a lo que nos hace sentir bien porque estamos obsesionados midiendo si tenemos más o menos bienes y placer que el resto [...] El punto no es encontrar gratificaciones personales, sino medir si esa gratificación es superior o inferior a la de los demás. Lo que produce felicidad es superar a los otros, más que experimentar un sentimiento de realización personal. Los chinos tienen una maldición rara: "Ojalá vivas en tiempos interesantes". Para los chinos, el interés de los tiempos 
es directamente proporcional a los problemas que plantean. La bendición consistiría en vivir en una época aburrida, donde cada uno pudiera dedicarse sin interrupciones ni sobresaltos a su vida íntima y familiar, que es la que da satisfacciones. Pero para ellos la posibilidad de hacer frente a esta marea de acontecimientos es lo que le da el verdadero interés a la vida. La palabra crisis en japonés está compuesta por dos caracteres: uno significa "peligro" y el otro "oportunidad". Los japoneses siempre intentan buscar formas de sacar algún beneficio ante situaciones dificultosas; el mejor ejemplo, quizás sea cómo resurgieron después de la Segunda Guerra Mundial.

El filósofo coreano afincado en Berlín, Byung-Chul Han ha escrito un libro que lleva por título La sociedad del cansancio (2017). Para este autor cada época tiene sus enfermedades emblemáticas. La época bacterial acabó con la invención del antibiótico, la época viral gracias a la técnica inmunológica. Pues bien, en el comienzo del siglo XXI la pandemia no es bacterial, ni viral, es neuronal. La depresión, el restrés -estrés negativo en oposición al eustrés o estrés positivo-el trastorno por déficit de atención con hiperactividad (TDAH), el trastorno límite de la personalidad (TLP) o el síndrome de desgaste ocupacional (SDO), etc. definen el panorama de comienzos de siglo. Estas enfermedades no son infecciones, sino estados patológicos que siguen a su vez una dialéctica, no la de la negatividad, sino la de la positividad, es decir, se producen por exceso de actividad. El autor también hace un interesante análisis de cómo el hombre de hoy se destruye a sí mismo en la búsqueda incesante del éxito y del poder, en una carrera narcisista en que solo se contempla a sí mismo como si fuera el centro del mundo. Una carrera vertiginosa que, para este filósofo, conduce a ninguna parte. Al menos, a ninguna parte a la que queramos ir, pues todo nos conduce a algún sitio; a veces a sitios a los que no deseábamos haber llegado.

¡Sí! Estamos en la sociedad del cansancio y una persona cansada es una persona malhumorada, que se relaciona mal consigo misma, con su entorno familiar, que no puede disfrutar de la amistad y que no valora lo más sencillo y hermoso que le da la vida, porque simplemente no puede verlo aunque lo tenga delante de sus propias narices. $\mathrm{Y}$ todo, por conseguir aquello que 
siempre había anhelado y que pensaba que al alcanzarlo, al fin, podría descansar y ser feliz. No es casualidad que el neoliberalismo haya equiparado el éxito profesional con la realización personal, cosa que no conduce más que a la autoesclavitud de las cosas y circunstancias, aunque uno crea ser libre. ¿Qué busca un adolescente o un joven hoy? Tener éxito personal y profesional y con ello la felicidad. ¿Cómo piensan lograrlo? Con dinero, buena presencia, diversión, etc. ¿Cree el dilecto lector que son muchos los jóvenes que han pensado, en algún momento, que tener éxito profesional es un medio excelente para servir mejor a la sociedad en la que vive?

La maldición china viene a decir: ojalá te veas arrastrado por la espiral de acontecimientos que te toque vivir $y$ no tengas ni un segundo de paz. O lo que es lo mismo, ojalá te olvides de ti mismo y tengas una vida tan vacía que, por hacer lo urgente, nunca llegues a hacer lo importante. De ahí se deduce que una vida feliz sería entonces una vida tranquila, pacífica y familiar en la que nadie anduviera corriendo continuamente para satisfacer no sé cuántas necesidades que creemos tener y que siempre dan pie al siguiente escalón de los deseos, dígase riqueza, poder, pasión o posición social. Sin embargo, la sabiduría china parece tenerlo todo previsto porque la segunda de las maldiciones dice, precisamente, que "ojalá que se cumplan todos tus deseos", o lo que viene a ser lo mismo: ten cuidado con lo que deseas, no sea que tus deseos se hagan realidad.

La felicidad no es enemiga de actitudes como paciencia, renuncia y esfuerzo. El secreto está en que el esfuerzo y la renuncia no deben considerarse como una fuente de infelicidad, sino, como una posibilidad de llegar a una situación mejor en la vida. La "procrastinación" puede ser, y lo es, una fuente de felicidad...

La clave del éxito en la vida se resume en tres conceptos: esfuerzo, talento y humildad. A los estudiantes se les puede decir: Lo que garantiza un éxito académico estable es la planificación del trabajo personal, o dicho de forma más simple, un horario de estudio bien planificado y realizado. Es la manera de acumular eficientemente el esfuerzo. Se trata de trabajar con un horario de estudio y sus resultados son incomparablemente mejores que los de 
cualquier alternativa (es lo que se llama el esfuerzo autorregulado).

Les propongo algunos ejemplos: decía Pablo Sarasate (1844-1908): “He practicado 14 horas diarias durante 37 años tocando el violín y ahora me Ilaman genio". El basquetbolista Larry Bird encestó en el último segundo de una final y su equipo ganó el partido y el campeonato con aquella canasta. Un periodista le preguntó: “¿Qué se siente al tener tanta suerte?". La respuesta de Larry fue "Curiosamente, cuantas más horas practico este tipo de canastas, más suerte tengo". Y Pablo Picasso decía: "Que cuando llegue la inspiración te encuentre trabajando". El éxito viene con un $10 \%$ de inspiración y un $90 \%$ de transpiración.

El esfuerzo solo se justifica y comprende cuando vamos en búsqueda de horizontes mejores. Si no es así estamos ante el mito de Sísifo. Pero hay que reconocer que no es fácil llegar a ser feliz; por eso, Diógenes (el cínico) iba en búsqueda del hombre feliz con un candil en pleno día. El hombre de la posmodernidad anda tan perdido en la selva de la vida que Ernesto Sábato ha escrito: "Estamos todos tan desorientados que hemos llegado a confundir la felicidad con salir de compras en los grandes almacenes". Para conseguir la felicidad se ha pasado de una ética del esfuerzo a una ética de la diversión y la superficialidad.

"Los millonarios, dice Zizek (2018) conducen el Titanic hacia el iceberg, $y$ en lugar de intentar cambiar el rumbo, acaparan recursos previendo el naufragio. Es la mirada de los ricos individualistas que piensan que pueden comprar un barco; el problema es que ese barco es de oro y se hunde en el mar. Para bien o para mal, todos estamos en el mismo barco [...] Para evitar el impacto es necesario frenar en seco y cambiar de rumbo antes de que empiece la huida hacia los botes salvavidas". La humanidad lleva décadas administrándose dosis insostenibles de consumo. Unos pocos disfrutan, pero la mayoría ve la fiesta desde fuera. Todos pagarán la factura cuando la fiesta termine. Las películas de Hollywood nos enseñaron que pase lo que pase, en el último segundo de la escena, aparecerá alguien-el héroe-para evitar el desastre inminente. Los malos de la película atacan el planeta Tierra provocando aumento de temperatura global, deshielo de los casquetes polares, 
desertización y extinción de especies. Frente a tanto desastre, ¿piensa que la tecnología será la solución?

El Dalai Lama (que significa en lengua tibetana Maestro de gran sabiduría), premio Nobel de la Paz en 1989, estuvo en Lima en mayo del año 2006. Tanto en Lima comoelCuzcoimpartiócharlasydijo ideas interesantes. Transcribo algunas: "El sufrimiento es una circunstancia que debía enfrentarse, pero si nuestra mente está feliz, nada externo puede alterarla". El ilustre visitante también habló a los empresarios: "Los empresarios deben trabajar por el bienestar social, que también es el suyo, porque tienen más recursos para proveer educación y salud", afirmó. Dejó en claro una cosa: "No debemos olvidar el valor y la importancia de la compasión, el perdón y la autodisciplina".

Un empresario de Lima solicitó una entrevista privada con el Dalai Lama; la entrevista duró unos pocos minutos; al salir de la misma le preguntaron sus amigos. ¿Qué te ha dicho el Dalai Lama en la entrevista? El empresario contestó: "Llegué a la sala, lo saludé, me miró fijamente a los ojos y al cabo de un tiempo me dijo: "Tú tienes derecho a ser feliz". Permaneció en silencio otro buen tiempo y me despidió muy cortésmente". Había sido tan impactante la frase, que en ese momento descubrió esa realidad. El aprendizaje debe contribuir a que las personas sean más felices. “Una escuela tiene calidad cuando el estudiante aprende en ella, en el momento oportuno y se siente feliz aprendiendo" (Bradasky,). Lo cognitivo y lo afectivo tiene que concretarse en las programaciones para que el docente sepa cómo se van a ir trabajando ambos conceptos a lo largo del curso. "Hoy en día hay demasiados niños brillantes y motivados que se vuelven adultos infelices", porque no han tenido un desarrollo armónico de lo cognitivo y lo emocional.

Actualmente, hay colegios que se han centrado en el bienestar de los estudiantes como la clave en la educación. Se ha confirmado que al desarrollar técnicas para enfrentar la vida y los desafíos personales, no solo genera que los estudiantes obtengan un buen desarrollo en los ámbitos sociales y personales, sino también en los académicos. En el Wellington College de Londres se enseña, desde el año 2006, la asignatura de La felicidad en todos los grados, una hora semanal. En esta institución se ha entendido que la 
clave de la educación es el bienestar de los estudiantes. Definen el bienestar y la felicidad como"un estado dinámico, en el que el individuo es capaz de desarrollar su potencial, realizar trabajo productivo y creativo, construir relaciones sólidas y positivas con los demás, y contribuir a su comunidad al adquirir un sentido de propiedad y propósito para con la sociedad".

La asignatura de Felicidad es impartida por profesores especialistas que tratan temas esenciales que influyen directamente en el bienestar de sus alumnos, bajo la convicción de que "el desarrollo de las emociones es igual o más importante que el desarrollo intelectual". Los profesores trabajan semanalmente alguna habilidad específica con los estudiantes, que les permita un mejor desarrollo, como por ejemplo: métodos para dormir bien, cómo eliminar tensiones, cómo sobrellevar desilusiones, pérdidas o fracasos, cómo descansar la mente, cómo tratar la ansiedad y el estrés, etc. $Y$ algunos de los temas principales que tratan en sus dinámicas clases son los siguientes:

- Debates sobrelas emociones paraque los menores aprendan a identificarlas y a entender bien lo que sienten de acuerdo a diferentes situaciones. Así, los niños podrán controlar y regular sus emociones y así lograr reducir la violencia escolar, fomentar la responsabilidad y capacitar los niños para afrontar las incertidumbres con comprensión.

- Fijar objetivos vitales positivos para promover una buena enseñanza que refuerce la autoestima y el desarrollo de los niños, en lugar de decirles que el objetivo es sacarse buenas notas, ganar la competencia de atletismo, obtener diplomas, etc.; es bueno incentivarlos en base a lo útil que les será ese aprendizaje para la vida.

- Enseñar a los niños a sobrellevar la tensión para que de esta forma logren cosas tan simples como respetar los turnos, trabajar a conciencia y sin apuro, y también logren trabajar en equipo y en sana competencia, adquirir tolerancia a la frustración y desarrollar la paciencia y el esfuerzo. Promover y potenciar la empatía, es decir enseñarle a ponerse en el lugar del otro como una de las claves para desarrollar la sociabilidad y el buen ambiente escolar. Los niños, además, adquieren un compromiso 
a ser mejores personas y a ayudar a quienes más lo necesiten, inculcándoles desde pequeños la posibilidad de que ellos pueden cambiar el mundo para mejor, responsabilidad que potencia su autoestima, haciéndolos creer en objetivos positivos.

Por otra parte, el colegio también integra a los padres y familias de los estudiantes, impartiendo seminarios y charlas sobre felicidad, para que así todo el entorno de los menores esté alineado en el mismo propósito de felicidad y bienestar, porque creen firmemente que la felicidad está al alcance de todos y que el desarrollarla requiere de un esfuerzo y depende de cada uno. Aspirar a ser "la mejor versión de sí mismos" y a "tener una biografía feliz" es legítimo, pero no tiene que ser una obsesión.

El éxito alcanzado se tradujo no solo en el bienestar de los estudiantes y profesores, sino también en lo académico y el Wellington College se convirtió en el colegio que más ha mejorado sus resultados académicos en el Reino Unido durante los últimos años.

Actualmente existen, a nivel mundial, índices que determinan el desarrollo económico, (PBI), la felicidad (FBI), etc. El índice de Felicidad Bruta Nacional (FBN) - Felicidad Interna Bruta (FIB) es un indicador propuesto por Jigme Singye Wangchuck en 1972, rey de Bután, como respuesta a las críticas a la pobreza de su país. En lo profundo de la cordillera del Himalaya, en la frontera entre China e India, se encuentra el Reino de Bután de un millón de km2. Su primer ministro de Bután, (en el 2013), Tshering Tobgay, se ha propuesto como misión, al gobernar el país, conseguir la mayor felicidad de sus habitantes y a su vez establecer un estándar mundial para la preservación del medio ambiente por encima del crecimiento económico. Para este país la Felicidad Interna Bruta (FIB) es más importante que el Producto Interno Bruto (PIB).

El economista Richard Layard ha propuesto sustituir un parámetro económico tan cuestionado como el PIB por el índice de felicidad (FIB). La ONU instituyó, en el 2012, el 20 de marzo como el día internacional de la Felicidad. David Cameron, primer ministro del Reino Unido, tras anunciar en 2007 los mayores recortes económicos de la historia de su país, decidió que era el momento para adoptar la felicidad como 
índice; los británicos no debían pensar sólo en meter dinero en el bolsillo, sino en lo que les hace más felices. Hasta Venezuela tiene un viceministerio para "la felicidad del pueblo".

Los pilares del desarrollo que posibilitan un FIB elevado son los siguientes:

- Desarrollo socioeconómico sostenible e igualitario

- Preservación y promoción de los valores culturales

- Conservación del medio ambiente

- Gobierno honesto

El FBI se contrapone al $\mathrm{PBI}$, pues este tiene un carácter económico. El índice de $\mathrm{FBI}$ tiene los siguientes indicadores: salud pública (física y psicológica), estabilidad laboral y empleo del tiempo libre, diversidad medioambiental, goce pleno de los derechos humanos (educación, cultura, etc.), vitalidad de las comunidades. El índice de felicidad quiere medir la calidad de vida en términos objetivos para determinar el bienestar de los ciudadanos y el progreso del país.

En el marco de la celebración del Día Internacional de la Felicidad (20 de marzo del 2019), Activa Research, en sociedad con WIN (Worldwide Independent Network of Market Research, 2019), dieron a conocer un estudio realizado en 40 países sobre los niveles de felicidad que existen en varios países del planeta Tierra. Entre octubre del 2018 y enero del 2019 se entrevistaron 30.890 personas de 40 países. El estudio sostiene que el $52 \%$ de los entrevistados dicen ser felices, por debajo del $57 \%$ observado en 2016. Filipinas es el país con mayor nivel de felicidad declarada por sus habitantes (78\%), mientras que Palestina registra el nivel más bajo en el ranking mundial de este indicador (24\%).

Las variables consideradas en el estudio fueron: el éxito económico, la familia y la salud, entre otras. También incluyeron el nivel de educación, como indicador relevante. En ese sentido, cabe preguntarse ¿cuánto influye la educación en la felicidad? El estudio indica que la educación juega un papel crítico en el estado de felicidad. Aquellas personas que no tuvieron acceso a educación o no finalizaron su enseñanza básica, muestran muy bajos niveles de felicidad. En Chile, por ejemplo, las cifras indican que quienes no tienen educación o solo tienen educación básica, reportan un $42 \%$ de felicidad, mientras que aquellos que cuentan con 
educación de posgrado es de $79 \%$ y este porcentaje desciende según baja el nivel de educación. Quienes tienen educación superior completa se declaran felices en un $61 \%$, con educación media completa alcanza el $60 \%$ y con educación básica completa o incompleta esa cifra llega a $42 \%$.

Y en cuanto a edad, según indica el estudio para Chile, las personas entre 40 y 49 años se declararon más felices (69\%). Luego viene el grupo entre 30 a 39 años (62\%), el de 18 a 29 años (54\%) y el de 50 años y más (52\%). Llama la atención el bajo nivel de felicidad de los jóvenes chilenos. Si se analiza ese segmento de edad a nivel mundial, si bien históricamente era el grupo más feliz, se observa una caída en el indicador en esta última medición. ¡Qué está pasando en el mundo con la felicidad de los más jóvenes...! En cambio, nos encontramos con que los adultos entre 30 y 49 de declaran más felices y este diagnóstico se observa en el resto de los países del estudio. Quizá los jóvenes actuales sigan la consigna de mayo del 68: "Seamos realistas... Pidamos lo imposible". Quizá se haga realidad en ellos este dicho: A los veinte años reina la voluntad, a los treinta el espíritu y a partir de los cuarenta el juicio y la razón.
Easterlin (s/f) plantea la relevancia que tiene el factor educación con la felicidad personal. El experto de la Universidad de Pensilvania, realizó un metanálisis de más de 30 estudios realizados en 90 países entre 1946 y 1970 sobre la felicidad, y encontró que el crecimiento económico no conduce a una mayor felicidad. Easterlin descubrió que la educación mejoraba los ingresos económicos, pero así como los ingresos de una persona aumentaban con el tiempo, su felicidad no. Sin embargo, si la felicidad comenzaba temprano en la vida de una persona, para aquellos que adquirían más educación, la felicidad persistía en su vida. En estas condiciones, las personas con más educación eran más felices que las que tenían menos. 


\section{Las happycracia o la felicidad como imperativo de la vida}

La socióloga israelí Eva lllouz y el psicólogo español Edgar Cabanas han escrito recientemente un libro titulado Happycracia. Cómo la ciencia y la industria de la felicidad controlan nuestra vida (2019). Los autores advierten al público que estamos ante una nueva forma de manipulación de las personas, utilizando aquello que les es más querido y que más buscan: la felicidad. El libro es una denuncia contra la manipulación de la industria de la felicidad la cual se fundamenta en una interpretación sesgada de legitimidad científica en la psicología positiva. "Este no es un libro contra la felicidad, sino contra la visión reduccionista de la "buena vida", que la denominada ciencia de la felicidad presenta y que cada vez está más extendida", dicen los autores.

"El neologismo happycracia viene de happiness (felicidad), siendo happ, un verbo inglés que significa tener suerte. $Y$, sin embargo, hoy la felicidad no se concibe como algo que tenga que ver con la suerte, con la buena fortuna o con las circunstancias. El sufijo cracia proviene del griego, y significa poder y autoridad. Se utiliza para mostrar cómo la felicidad se integra en el tejido de poder y se utiliza como criterio principal para tomar decisiones sobre la vida de las personas bajo simples argumentos de autoridad. En este caso es la autoridad científica de la psicología positiva que es utilizada como uno de los grandes aliados de esta idea de la felicidad actual" explica Cabanas a Ordóñez (2019).

Como hemos visto, la felicidad siempre ha estado presente en la mente de las personas; el humano, aunque no sabe qué es ser feliz, siempre ha buscado la felicidad de diversas maneras. El problema es que no sabemos "qué es ser feliz" ni "cómo ser feliz"; de hecho ningún psicólogo positivo, ningún científico de la felicidad, ha definido nunca en qué consiste el estado final de felicidad, y sin embargo lo tenemos como objetivo en la vida y no siempre encontramos el camino que conduce a ella. El camino de la felicidad se parece más a una ruta de senderismo a través de una montaña que a una autopista. Para recorrer la ruta hay que mirar una señal, recorrer cierta parte del camino hasta llegar a la siguiente indicación, y así hasta culminar el viaje, que a veces se torna incierto y peligroso. Por el contrario, en la autopista todo 
está señalado de antemano; se sabe los kilómetros que faltan, la velocidad que puedes llevar y en consecuencia el tiempo que se tarda en llegar a destino. Con la felicidad no ocurre lo mismo $y$, sin embargo, hoy se ha convertido en algo omnipresente, en el motor fundamental de nuestras vidas, más aun, se ha convertido en un imperativo de la vida. Si no consigues ser feliz -o por lo menos aparentarlo- parece que algo has omitido o has hecho mal en tu vida.

La expansión por todo el mundo, durante las últimas décadas, de la psicología positiva es la razón de la búsqueda, a cualquier precio, de la felicidad. La felicidad es concebida como algo que cada persona crea o destruye, a través de la responsabilidad y autonomía personales. Esta felicidad es individualista: es feliz el que quiere ser feliz, sin importar las circunstancias de tipo personal, social, familiar, económico y cultural, que le rodean. Todo depende de la actitud del individuo frente a las circunstancias de la vida. Es la religión del uno mismo, del "cree en ti mismo", "cree en tus posibilidades", "focalízate y gestiona tu vida interior"... El hombre es considerado como una isla que no tiene nada que ver con otras islas o continentes.
Cada uno puede diseñar a su gusto una biografía feliz siempre que vea la vida con un enfoque positivo. La happycracia es la enfermedad de querer ser feliz a toda costa. "Mejora tu felicidad en dos meses"; esta es la promesa fantástica de Happify una aplicación tecnológica basada en "la ciencia" que "mejora la salud emocional". El mundo puede estar derrumbándose a su alrededor pero con un enfoque positivo cada sujeto puede cambiar las tornas a la situación; todo depende de uno mismo, según se lo dijo su gurú o su coach (Ordóñez, 2019).

Illouz y Cabanas (2019) señalan que se propone una felicidad que es un estilo de vida que apunta hacia la construcción de un ciudadano individualista, que piensa que no le debe nada a nadie, sino que todo lo que tiene se lo merece. Sus éxitos y fracasos, su salud, su satisfacción, no dependen de cuestiones sociales sino de él mismo y de su correcta gestión de sus emociones, pensamientos y actitudes.

En realidad, no han descubierto nada nuevo; todo se apoya en la psicología positiva de Seligman (2002) que, según su definición, es"el estudio científico de lo que hace que la vida merezca la pena ser vivida". A comienzo, y hasta mediado el 
siglo XX, la psicología estuvo influenciada por las ideas de Freud quien se concentró en el estudio de las patologías del ser humano en detrimento de sus aspectos positivos. A inicios del siglo XXI, Martin Seligman junto con su colega Mihaly Csihzenmihalyi, se preocuparon del estudio de la psicología humana desde una perspectiva más positiva; así surgió la psicología positiva que se centra en el estudio de las condiciones y los procesos, aspectos que contribuyen al óptimo funcionamiento de las personas, grupos e instituciones y que les permite alcanzar la felicidad y la prosperidad. Las preguntas que se formula la psicología positiva son las siguientes: ¿qué hace que una vida sea plena?, ¿cuál es el camino para conseguirla?

Según Seligman (2002) hay tres vías para llegar a una vida plena: a) cultivando en la vida emociones positivas, es decir, tener la mayor cantidad de momentos felices en la vida. Es una propuesta netamente hedonista. Estos momentos pueden alcanzarse a través del savoring savorear el momento presente deleitando los sentidos de la forma más genuina posible, o bien a través del mindfullnnes que es conseguir la atención plena de los pensamientos, emociones y acciones. b) El compromiso personal efectivo con el propio trabajo y con la capacidad de experimentar en ella el estado flow, que es el estado de concentración tal que parece que el tiempo se ha detenido. c) La búsqueda de una vida con sentido (meaningfull live); es el desarrollo personal pleno para ayudar a los demás; esta posibilidad se da a través de la familia, el trabajo, la escuela, el servicio a la comunidad, etc. Es poner las capacidades personales al servicio de los demás para dar un sentido a la vida.

Últimamente Seligman (2009) ha incluido una cuarta vía: d) establecer vínculos positivos como vía de acceso a la felicidad, pues facilitan el bienestar psicológico (la vida social).

La psicología positiva lleva veinte años afirmando que ha descubierto las claves y fórmula de la felicidad, como si fuera una ecuación. Afirman que la felicidad se debe, en casi el $90 \%$, a factores personales y las circunstancias o factores sociales (nivel social, nivel educativo, ingresos, sexo, cultura, etc.) importan poco o no importan. Las circunstancias no nos hacen felices, somos nosotros los que nos hacemos felices o infelices, pues todo es psicológico. Estos planteamientos psicológicos no tienen en cuenta que 
los trabajadores, que viven en un estrés constante, no lo tienen porque no gestionen bien sus emociones, sino porque la situación laboral es precaria, insegura y muy competitiva; no son felices porque no gestionan su entorno adecuadamente, sino porque su entorno es causa de su infelicidad.

La utópica formula de la felicidad de Seligman (2002) señala:

$$
\begin{aligned}
\mathrm{F}(\text { Felicidad })= & \mathrm{R}(\text { Rango justo })+ \\
& \mathrm{V} \text { (Voluntad })+ \\
& \mathrm{C} \text { (Circunstancias })
\end{aligned}
$$

50\% Predisposición genética

40\% Actitud personal

10\% Educación / Ingresos

¿Solo un $10 \%$ de la felicidad se explica con factores exógenos? ¿Para qué quieren los ricos amontonar su riqueza? ¿Para ser infelices? Parece que esto no se comparece con la realidad. Al respecto Illouz y Cabanas (2019) explican que,

la felicidad se ha revelado como una forma muy poderosa de control social porque contiene la idea de que conseguirla es por nuestro propio bien y que nos hace bien. La idea de felicidad ha venido de alguna forma a secuestrar todos aquellos significados que tienen que ver con lo bueno, con los éxitos y es una forma de responsabilizar a las personas por sus propios éxitos, buscando mantenerse de forma saludable, ser productivo, etc. Ofrece una solución a problemas 
que son estructurales, pero lo hace de manera individual, de forma que, con este planteamiento, lo que hace es ocultar o desdibujar la verdadera causa de los problemas sociales.

Es como el control planteado por Aldous Huxley en su novela Un mundo feliz. En esta novela los protagonistas se someten de forma voluntaria a cierto control, pues las personas lo hacen porque creen que el control es por su propio bien. Eso se llama "la manipulación perfecta". Ya sabemos cómo acaba la novela: con la imagen del cadáver de John girando lentamente en el aire suspendido de una viga.

Según la revista Forbes, el $40 \%$ de las 500 mayores empresas de EE.UU. utilizan el coaching con sus empleados de manera habitual. Illouz y Cabanas (2019) apuntan:

en las empresas obligan a pasar cursos de resiliencia, coaching y mindfulness para aprender que eres tú el que ha de encontrar la forma de estar mejor en el trabajo, pues de eso depende la productividad. Y en la educación se dice que el objetivo es hacer que los estudiantes sean felices. Habría que ver qué tipo de ciudadano queremos construir, si un ciudadano crítico y centrado en el conocimiento del mundo o un estudiante puramente emocional centrado en el conocimiento de sí mismo.

No creo que los empresarios estén interesados directamente en la felicidad de sus trabajadores; más bien creo que es una forma sibilina de producir más y mejor teniendo trabajadores felices en el trabajo. Hay empresas que contratan su personal en función de sus niveles de felicidad; prefieren gente optimista y que no se queje; cada vez más estos criterios priman sobre los conocimientos técnicos del empleado. Ciertamente, ¡si no hubiera existido la ciencia de la felicidad, el mundo empresarial la habría inventado...!

La psicología positiva social admite que las circunstancias influyen sobre la felicidad de los ciudadanos, pero como cambiar el contexto es muy caro, prefieren cambiar la psicología del ciudadano para que sea feliz en cualquier circunstancia.

En ese sentido, concluyen Illouzy Cabanas (2019) que: 
declarar hoy que no eres feliz es vergonzoso, como si hubiéramos perdido el tiempo o hubiéramos hecho algo mal y podríamos hacer algo y no lo hacemos, somos personas negativas [...] Este concepto de felicidad tiene raíces norteamericanas y no contiene las claves para la buena vida. La única buena noticia es que en esta noción de felicidad hay valores más importantes: la buena vida es justa, solidaria, íntegra, comprometida con la verdad. No es estar preocupados por nosotros mismos todo el tiempo.

Por otra parte, hay que decir que este concepto de felicidad no es científico, no procede de las ciencias biológicas humanas, sino que es de origen ideológico. Proviene de las ciencias sociales que invariablemente parten de hipótesis culturales y morales no siempre comprobadas científicamente. Seligman es un psicólogo y escritor estadounidense conocido por sus aportes a la Psicología positiva y a la indefensión aprendida, seguido por sus colegas Diener y Mihaly Csihzenmihalyi, Jamieson, Peterson y Vaillant, son los grandes aliados para legitimar el discurso de la ideología de la happycracia.

Una ideología es un conjunto de pensamientos erráticos que buscan determinados intereses y "el fin justifica los medios". Pueden ser intereses económicos, de poder, de raza, sociales, etc. La ideología de la felicidad asume una propuesta sobre qué es y sobre lo que debe ser la naturaleza humana y cómo se debe comportar; son propuestas o ideas no comprobadas de forma científica, pero tienen una proyección y un proyecto político y económico claro sobre las personas y la sociedad.

La psicología positiva posee elementos valiosos, pero se ha utilizado de forma sesgada para justificar las hipótesis de la happycracia, y el neoliberalismo económico la ha convertido en una ideología individualista, concibiendo al serhumano como autónomo y autosuficiente, que tiende a focalizar en el individuo todo el peso y toda la explicación de las dinámicas sociales. No existen problemas sociales; lo que existen son problemas individuales.

El ser humano tiene derecho a la felicidad, pero ahora el derecho se está convirtiendo en un deber. Más que pedir y desear que las personas sean felices, ahora se les exige que sean felices; la 
felicidad se ha convertido en un deber más. La felicidad, dicen Illouz y Cabanas en Happycracia se ha convertido en "una obsesión", "un regalo envenenado", al servicio del sistema económico actual. En estos últimos años la autoayuda, el coaching y el mindfullness, bajo el pretexto del deber de ser feliz -con una propagada bien financia por empresas $y$ fundaciones- se han colocado en las agendas académicas, políticas y económicas de muchos países. La industria de las terapias positivas, servicios de coaching o el mindfullness, prometen "soluciones efectivas y basadas en la ciencia para una mejor salud emocional y mayor bienestar en el siglo XXI". Son una ciencia y una industria que venden una noción de felicidad, "al servicio de los valores impuestos por la revolución cultural neoliberal"; ahora ya lo sabemos: no hay problemas sociales estructurales sino deficiencias psicológicas individuales.

En esta línea, riqueza y pobreza, éxito y fracaso, salud y enfermedad, son fruto de nuestros propios actos, no del contexto en el que vivimos, que es el que nos crea la economía neoliberal. Estamos obligados a ser felices y, si no lo somos, debemos sentirnos culpables por no sobreponernos a las dificultades. Puedes ser feliz si quieres, pues si sufres es también porque quieres, "eres sospechoso de querer seguir mal, de no poner los medios necesarios para dejar de estar mal, para dejar de estar ansioso o dejar de sentirte impotente", asegura Cabanas. Es una visión reduccionista e interesada de la vida saludable que predica la ciencia de la felicidad.

La felicidad se ha convertido en punto central hasta en foros económicos neoliberales, --como el Foro Económico de Davos--, que ha invitado al mismo al monje budista Mathieu Ricard considerado "la persona más feliz del mundo" acreditado por la Universidad de Winsconsin midiendo su actividad cerebral. Hay que decirlo con claridad: la actual noción de felicidad está al servicio de los valores de la revolución económica neoliberal. Que la felicidad es hoy omnipresente es indudable. Veamos en las librerías de los grandes almacenes qué tipos de libros aparecen a la vista de los clientes en primer lugar; todo son libros de autoayuda. En Amazon había hace unos años 300 títulos con la palabra felicidad, ahora hay 2.000. En 2015 el sociólogo británico William Davies publicó un libro titulado La industria de la felicidad en el que pone en alerta sobre el lado oscuro 
del fenómeno de la felicidad a la carta. "Las técnicas para medir nuestro estado de ánimo, los algoritmos utilizados para analizar las emociones se ponen al servicio de los intereses económicos y políticos", dice Davies. Nuestro estado emocional se ha convertido en una mercancía más, comercializada de distintas maneras y presentada en distintos envoltorios: coaches de desarrollo personal, entrenadores de mindfullness, libros de autoayuda, etc.

La industria de la felicidad es muy lucrativa, está muy extendida y viene revestida por el argumento científico de la psicología positiva. Vender algo con el aval de legitimidad científica hace que sea un producto valioso y deseable. Por eso, hoy en día, la felicidad es un producto que se compra a través de terapias, servicios, guías, consejos, coaching, mindfullness, etc. Es un producto barato de producir y que genera beneficios enormes. Según la Federación Internacional de Coaching, solo en EE.UU. el mercado del Coaching alcanzó los 955 millones de dólares en 2015, frente a los 705 millones de 2011 y su estimación es de 1,300 millones de dólares para 2022. El mercado de la autoayuda está en expansión y es una tarta a la que se apunta el mundo académico. Hay otro negocio paralelo no menos sustancioso: la formación de coachs.

La felicidad también se ha convertido en un merchandising puro y duro imprimiendo tazas, felpudos y objetos caseros y variados. En Lima hay una radio que se llama Radio felicidad, queriendo mandar a sus oyentes el mensaje subliminal que quien la oye conseguirá ser feliz. Dos españoles han creado una tienda on line "de productos felices para alegrar al personal" que en 2017 tenía en nómina 150 empleados y facturaba 28 millones de euros.

Este mercado de la felicidad está tan bien diseñado que crea insatisfacción permanente. Esta felicidad tiene un componente dinámico e insaciable pues se basa en la idea que siempre puedes mejorar, que siempre falta algo, que siempre queda una dieta más que seguir, una terapia que probar, siempre se está en proceso, en continua búsqueda... La felicidad así entendida es una meta en constante movimiento, nos hace correr tras de ella de forma obsesiva. Y tiene que ver con una mirada hacia dentro; nos hace estar muy ensimismados, muy controlados por nosotros mismos y en constante vigilancia. Eso aumenta la 
ansiedad y la depresión pues se nos propone ser atletas de alto rendimiento de nuestras emociones; es la "vigorexia emocional". Corremos el riesgo de generar, en vez de seres satisfechos y completos, seres hipocondríacos emocionales, pues en el discurso de la felicidad lo que impone no es solo la idea de que no debemos estar mal, sino que aunque estemos bien, siempre podemos y debemos estar mejor.

Pero el hecho de que nunca se acabe de ser feliz hace que el sistema funcione muy bien como producto económico en la economía neoliberal. Un día te vas a un curso de mindfullness y cuando lo acabas pruebas otra cosa y otra y otra. Nunca se llega a la meta pues siempre se está en camino. Es como la utopía, pero ¿para qué sirve la utopía si nunca se va a alcanzar? Pues para eso sirve, para estar siempre en camino y en búsqueda continua.

En esta situación no es suficiente con no estar mal o estar bien, hay que estar lo mejor posible, y por eso, no sólo el que se encuentra mal necesita un experto, sino que lo necesita también el que se encuentra bien, para poder sacar el máximo rendimiento, -su mejor yo- para aprender nuevas técnicas de gestión de sí mismo y obtener nuevos consejos para conocerse mejor, ser más productivo y tener más éxito en la vida. 


\section{Conclusión}

Conseguir la felicidad y desarrollar una biografía feliz es una noble aspiración de los humanos. Conocemos la meta pero desconocemos el camino. Más aún, la sociedad actual nos ofrece tantos caminos para llegar a la meta que no sabemos cuál elegir.

Lewis Carrol narra en su novela Alicia en el país de las maravillas (2018) este cuento: Alicia se encuentra en una encrucijada de caminos y no sabe qué dirección tomar, entonces Alicia le pregunta al gato:

- ¿Quieres decirme, por favor, qué camino debo tomar para salir de aquí?

- Eso depende mucho de adónde quieras ir, responde el gato.

- Poco me importa a dónde ir, responde Alicia.

- Entonces, poco importa el camino que tomes, replicó el gato.

Ese es el problema: desconocemos la meta y, en consecuencia, no sabemos el camino que conduce a ella, pues para un barco sin rumbo, todos los vientos le son favorables, decía Séneca.

La pregunta clave es: ¿Conozco el camino y la calidad del camino que conduce a la meta de la felicidad? ¿No será que la happycracia se ha convertido en una cacocracia'? ¿La happycracia no nos estará robando la felicidad?

${ }^{1}$ Cacocracia $=$ procede de la palabra griega kakós que significa malo o malvado. De esta palabra griega viene la palabra latina cacus, sinónimo de ladrón (caco); pero el cacus es un ladrón inteligente, que sabe robar con habilidad para no ser atrapado, un ladrón fino y elegante de guante blanco, que roba sin recurrir a la violencia. La cacocracia será, pues, el gobierno de los que roban o el gobierno de los corruptos. Imagínese la desgracia de un país gobernado por la cacocracia junto con la ineptocracia. ¡Dios nos libre...!

.




\section{Referencias}

Aristóteles (1947). Obras de Aristóteles, edición de Patricio de Azcárate. Buenos Aires, Argentina: Florida.

Byung-Chul, Han (2017). La sociedad del cansancio. Barcelona, España: Herder.

Cardona, J. A. (2015). Filósofos helenistas. Barcelona, España: Batiskafo.

Carroll, L. (2018). Alicia en el país de las maravillas. Barcelona, España: Edhasa.

Collina, B. (2016). Sócrates. Maestro de la filosofía y de la vida. Madrid: El Comercio, Lima.

Epicteto (siglo I). Manual para la vida feliz. Madrid: Natura.

Easterlin, R. (s/f). Recuperado de https:// educrea.cl/cuanto-influye-la-educacionen-tu-felicidad/

Kant, E. (1990). Fundamentación de la metafísica de las costumbres. Madrid, España: Aguilar.

Kaplún, G. (1983). Indisciplinar la universidad. Recuperado de https:// www.academia.edu/3227139/ Indisciplinar_la_universidad

Illouz, E. y Cabanas, E. (2019). Happycracia. Cómo la ciencia y la industria de la felicidad controlan nuestra vida. Barcelona, España: Paidós.

Happycracia: Recuperado de https://www.lavanguardia.com/ cultura/20190320/461140462148/ felicidad-dia-internacional-libroshappycracia.html

Ordóñez, R. (2019). Se feliz, te estamos controlando. Entrevista a Cabanas. Recuperado de https://www. elindependiente.com/tendencias/ cultura/2019/03/17/se-feliz-te-estamoscontrolando/

Platón. (1946). Obras completas, edición de Patricio de Azcárate. Buenos Aires, Argentina: Florida.

Seligman, M. (2002). La auténtica felicidad. Barcelona, España: Vergara.

Seligman, M. (2009). Special Lecture. Ponencia presentada en First World Congress on Positive Psychology. 
International Positive Psychology

Association. Philadelphia, EE.UU.

Séneca, L. A. (2018). Cartas a Lucilo.

Barcelona, España: Planeta.

Zizek, S. (2018). Recuperado de

https://www.elclubdeloslibrosperdidos.

org/2018/07/las-11-frases-mas-

interesantes-del.html

\section{Para citar este artículo:}

Latorre, M. (2019).

Felicidad versus happycracia.

Revista Educa UMCH, 13(1).

https://doi.org/10.15756/educaumch.v7i13.97 